\title{
Technological factors affecting green innovation: Evidence from the manufacturing sector in Vietnam
}

\author{
Nguyen Minh $\mathrm{Ha}^{1}$, Pham Anh Nguyen ${ }^{2 *}$, Nguyen Bach Hoang Phung ${ }^{3}$ \\ ${ }^{1}$ President, Ho Chi Minh City Open University, Ho Chi Minh City, Vietnam \\ ${ }^{2}$ The Graduate School, Ho Chi Minh City Open University, Ho Chi Minh City, Vietnam \\ ${ }^{3}$ Thu Duc City People's Committee \\ *Corresponding author: anhnguyen223@gmail.com
}

\begin{abstract}
ARTICLE INFO
ABSTRACT

DOI: 10.46223/HCMCOUJS.

econ.en.12.1.2099.2022

Received: November $23^{\text {rd }}, 2021$

Revised: January $17^{\text {th }}, 2022$

Accepted: January $20^{\text {th }}, 2022$

Keywords:

compatibility; complexity;

green innovation; relative

advantage; SMEs;

technological factors; Vietnam

Firms' top priority is overcoming challenges to develop sustainably, generate profits, and gain a competitive advantage in the face of fierce market competition. Fostering technological innovation in the manufacturing process and investing in environmentally friendly manufacturing activities are important factors in eliminating waste and improving firm performance. This quantitative research had been examined in a sample of 400 manufacturing firms listed at industrial zones in Vietnam to determine the association between technological factors such as relative advantage, compatibility, simplicity, and green innovation. According to the research results, relative advantage, compatibility, and simplicity had a significant impact on green innovation in the manufacturing industry. From the result of this survey, manufacturing enterprises can adjust their business strategies properly to achieve better financial performance as well as a competitive advantage when implementing green innovation to develop their firms and protect the environment sustainably.
\end{abstract}

\section{Introduction}

Currently, the problems regarding environmental pollution, greenhouse gas, or climate change are becoming an urgent and global issue that each country must consider to take responsibility and cooperate with others to solve the problem. The rapid growth of the economy and the fast development of industrial parks are also a cause of pollution environment resource depletion. In addition, manufacturing firms are also considered as the main cause of environmental problems that every country has to deal with. Manufacturing operations often lead to different adverse issues regarding air pollutants, waste disposal, and fuel consumption. That harmful effect not being treated in the manufacturing process has polluted detrimentally not only to the environment locals' lives and health, and even enterprises' performance (Nishant, Teo, Goh, \& Krishnan, 2012). Businesses that pay little attention to benefits community, society, and the environment tend to focus on the profits of the organization (Nham, 2012). In addition, they are still afraid to invest in equipment and production technology to protect the environmental market because it consumes quite a lot of costs that can affect the profits of enterprises.

After a period of rapid economic growth, Vietnam has faced the enormous challenge of striking a balance between economic development and environmental sustainability (O'Rourke, 
2004). Despite increasing efforts, the available evidence has shown that environmental regulations in Vietnam have not been very successful in business compliance. Due to insufficient financial capacity and a lack of strict enforcement by Vietnamese authorities, important industries such as food, leather, and paper have low levels of regulatory compliance (Ho, 2015). In addition, small and medium enterprises often invest in temporary facilities to deal with environmental problems due to insufficient resources and high operating and maintenance costs, most of the waste treatment facilities only temporarily operate whenever the authorities conduct an inspection (Nham, 2012). According to Russo and Fouts (1997), an improvement or innovation in environmentally friendly manufacturing practices is associated with an improvement in corporate reputation and political acumen that helps businesses increase their attractiveness to environmentally conscious consumers and thereby improve sales significantly.

Green innovations have received great received much interest, and they are now recognised as one of the most important business strategies for dealing with today's competitive business environment. Green innovations can be defined as new environmental approaches involving new methods, production, or products that reduce the negative environmental impacts of business operations (Ruslan, Senin, \& Soehod, 2014; Seman, Zakuan, Jusoh, Arif, \& Saman, 2012). Wise businesses have recognized that changing their manufacturing methods can help to reduce the negative environmental impact while also successfully achieving the firm's goal in a highly competitive market (Walker \& Wan, 2012). In reality, green innovation can improve preventing environmental pollution, allowing businesses to save funds on operating costs, and reuse of materials through recycling, lowering environmental costs, and processing waste, as well as gaining a positive reputation, able to command a high price for products, and constantly increasing (Bansal, 2005; Christmann, 2004; Ho, 2015). Additionally, consumers increasingly put their trust in purchasing goods with a clear origin and product quality; therefore, products with highly green quality can help firms achieve a competitive advantage in the worldwide competitive market.

Understanding the factors affecting green innovation of enterprises is also an attractive topic gaining a lot of attention from researchers. Stakeholder pressure, technological factors, environmental regulations, company size, managerial characteristics, and human resources are all frequently mentioned in relevant studies (Etzion, 2007; Gonzalez-Benito \& Gonzalez-Benito, 2006). Green innovation can be a process of carrying out a new approach concerning techniques, processes, or technical innovation to reduce harm (Henriques \& Sadorsky, 2007). Additionally, technology characteristics such as relative advantage, complexity, and compatibility have proven to be important factors influencing the adoption of new technology.

It is recommended that those characteristics be considered when analyzing the adoption of green innovation since they are relevant in environmental management. As a result, the study intends to investigate the impact of technological factors on the green innovation of Vietnamese enterprises in the manufacturing sector. Understanding the primary determinants is necessary for enterprises' owners and top management to adopt efficiently green innovation to achieve the goal.

\section{Review of literature and research model}

\section{Technological factors}

Environmental experts have emphasized that green technology is one of the leading solutions to deal against climate change and is also an area full of future development prospects. Hence, countries pursuing green technology mean not only targeting the environment but also targeting an area that can create a new life force for the economy. Many studies were conducted to determine the most effective mode of technological innovation suitable for a specific industry, 
which also became a critical issue for businesses. According to Rogers (2003), technological innovation was the best way to achieve green transformation, while independent innovation became the primary driving force for promoting green development in technology-intensive industries.

There were many factors relating to technology, which were discussed about their influence on technological innovation, such as relative advantage, compatible ability, complexity, observable ability, usable element, intensive information, and uncertainty (Rogers, 2003). The relative advantage was the level at which innovation was considered as having more advantages than the changed idea. This could be measured in financial or social terms, which include performance, satisfaction, and convenience (Lin \& Ho, 2011). Compatible ability was the level at which innovation was considered as being suitable with the current value, experience, and need of firms (Rogers, 2003). Complexity was the level that innovation was regarded as being difficult in understanding and use as it increased the difficulty level in transferring knowledge and popularizing innovation (Rogers, 2003). Therefore, simplicity was the extent that an innovation is easy to understand, use, transfer knowledge and popularize innovation. This paper focused primarily on the three factors mentioned above in order to assess the impact of a technological factor on the green innovation of manufacturing firms.

\section{Green innovation}

Facing pressure from the government, stakeholders, and other institutions as well as the desire of achieving the successful goal, enterprises have difficulties in balancing the production process and protecting the environment. As a result, green innovation is considered as a new strategy for addressing that challenge in several business decisions (Berrone, Fsfuri, Gelabert, \& Gomez-Mejia, 2013). Furthermore, identifying factors influencing green innovation and the level of that innovation's impact on enterprise performance is critical for complying with environmental regulations, achieving firm performance in the manufacturing industry, and developing firms and the environment in a sustainable manner (Salihu, Nabegu, Abdulkarim, \& Mútapha, 2016).

Green innovation is defined as new or improved processes, techniques, practices, systems, and products allowing enterprises to constantly improve their production and business efficiency, while maintaining sustainable development, minimizing raw material costs, increasing energy productive forces, and being socially responsible for avoiding and minimizing harm to the environment (Beise \& Rennings, 2005; Kemp, Arundel, \& Smith, 2001). Green innovation can categorize into three sections involving green management, green product, and green process. Furthermore, it can be seen that green product innovation and green manufacturing processes have a strong relationship with firm competitive advantages. The result of many studies showed that green products and green processes had impacted positively on competitive advantages, green image, as well as the economic performance of enterprises (Chiou, Chan, Lettice, \& Chung, 2011; Rave, Goetzke, \& Larch, 2011).

Green innovation seems to focus on cooperation for environmentally sustainable development at every stage in the production of goods and services (Velena \& Ellenbecker, 2001). In other words, green consumption is environmentally responsible consumption while consumers consider the impacts on the environment when purchasing, using, disposing of different products, or using use other green services (Moisander, 2007). Therefore, enterprises have to pay much attention to the technology factor for the application of green innovation to increase competitiveness and consumer support. 


\section{Relationship between technological factors towards green innovation}

Researchers discussed the effects of various technological characteristics on innovation, such as relative advantages, compatibility, complexity, reliability, ease of observation, ease of use, information intensity, or uncertainty (Frambach \& Schillewaert, 2002; Jeyaraj, Rottman, \& Lacity, 2006; Rogers, 2003; Tornatzky \& Klein, 1982). Previous studies on green innovation suggested that technological factors involve the relative advantage, the simplicity, and the compatibility can have a greater positive impact on the adoption of green practices than others (Rogers, 2003; Sia, Teo, Tan, \& Wei, 2004; Weng \& Lin, 2011). Companies are more likely to adopt a technology that can provide better performance and higher economic boost than competing technologies and is more compatible with the company's current operational knowledge. According to the findings, relative advantage and technology compatibility have a positive impact on the adoption of green innovation (Kousar, Sabri, Zafar, \& Akhtar, 2017; Lin \& Ho, 2011; Tornatzky \& Klein, 1982). Contrastingly, great complexity's technology consists of numerous tacit knowledge requiring laborious efforts to learn and diffuse that makes it difficult to learn and share, leading to high difficulty to implement that technology. Hence, complexity was claimed to affect negatively the intention to innovate green practices (Kousar et al., 2017; Tornatzky, Fleischer, \& Chakrabarti, 1990). The minority of research concerning environmental concern have not empirically considered the effects of technological factors on green innovation. For filling this gap, the purpose of this research is to determine the impact of technological factors on the intention to adopt green practices in the context of Vietnamese organizations.

\subsection{Hypotheses}

From the results of the above studies and based on the innovation diffusion theory of Rogers (2003), It is expected that relative advantage, compatibility, and simplicity will have a significant impact on green innovation in Vietnam's manufacturing sector. The hypotheses of this research are given as follows:

H1: There is a positive relationship between relative advantage and green innovation of Vietnamese firms in the manufacturing sector

H2: There is a positive relationship between compatibility and green innovation of Vietnamese firms in the manufacturing sector

H3: There is a positive relationship between simplicity and green innovation of Vietnamese firms in the manufacturing sector

\subsection{The conceptual framework of the study}

Previous studies have focused on many factors affecting the innovation of green practices, including organizational factors, pressure from stakeholders, or environmental factors (AragonCorrea \& Sharma, 2003; Borsatto \& Amui, 2019; Guo, Xia, Zhang, \& Zhang, 2018; Kimberly \& Evanisko, 1981; Lee, 2008). This research will concentrate on and apply the innovation diffusion theory of Rogers (2003) to determine the effect of technological factors on green innovation in the context of Vietnamese manufacturing enterprises. The research framework of this research is proposed below: 


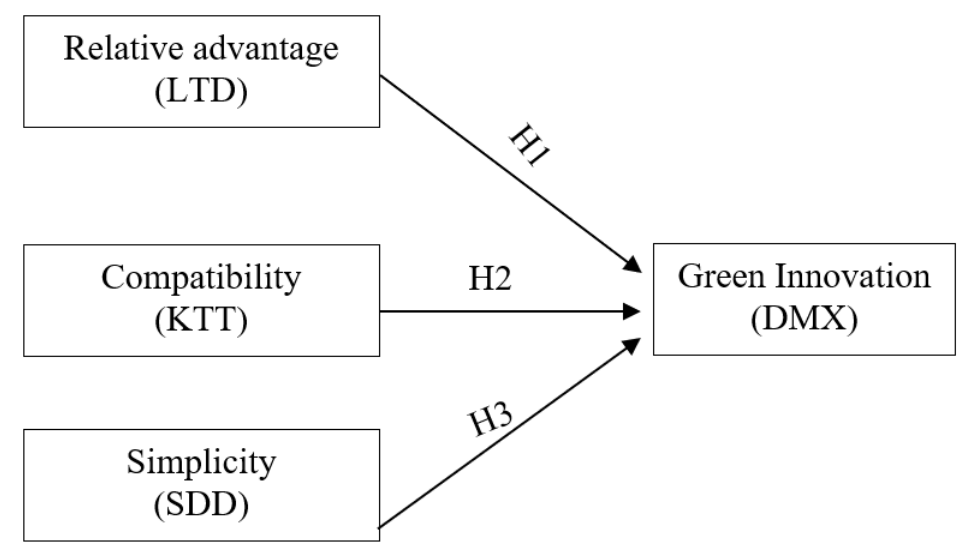

Figure 1. Research conceptual framework

Green practice adoption, as well as technological factors, are among the primary constructs highlighted in the current research paradigm. Each construct's measurement is based on previous research. Green innovation refers to a manufacturing company's decision to apply green practices to address environmental obstacles. In this study, we primarily focus on assessing green products and green processes, as discussed above. Green manufacturing management is likely to concentrate on minimizing emissions, conserving energy and natural resources, eliminating waste, and maximizing the use of materials. Green practices frequently involve improving energy efficiency, product durability or recyclability, reducing raw materials, using environmentally friendly raw materials, and eliminating hazardous building materials by changing or modifying product design in the manufacturing process using non-toxic compounds or biodegradable materials (Lin, Tan, \& Geng, 2013; Kivimaa \& Kautto, 2010). The green innovation scale was measured using a five-point Likert scale with 10 observed factors from Lai, Wen, and Chen (2003) and Wen and Chen (1997) studies, as well as 10 observed variables from qualitative scales. Furthermore, the technological factors were assessed using a five-point Likert scale with "strongly disagree" and "strongly agree" anchors. The relative benefit was calculated using respondents" opinions on whether the green practice could improve environmental and economic performance (Rogers, 2003; Sia et al., 2004). The degrees of perceived appropriateness between the green practice and the company's existing technologies and processes were used to determine compatibility (Lin \& Ho, 2011; Rogers, 2003). The ease with which the green practices could be learned and implemented was utilized to determine the level of simplicity (Lin \& Ho, 2011; Rogers, 2003). To quantify technological aspects, this study used the Rogers (2003) and Lin and Ho (2011) scales as well as qualitative scales. The measurement items for each factor were listed in Table 1.

\section{Table 1}

Measurement items

\begin{tabular}{|l|l|}
\hline \multicolumn{1}{|c|}{ Items } & \multicolumn{1}{c|}{ Indicator variable } \\
\hline \multicolumn{2}{|l}{ I. Technological factors } \\
\hline 1. Relative advantage \\
\hline LTD1 & Green technology innovation helps businesses be more competitive than competitors \\
\hline LTD2 & Green technology innovation helps businesses be more profitable \\
\hline LTD3 & Green technology innovation helps businesses increase the reputation \\
\hline
\end{tabular}




\begin{tabular}{|c|c|}
\hline Items & Indicator variable \\
\hline LTD4 & Green technology innovation helps businesses increase customers' loyalty \\
\hline LTD5 & Green technology innovation helps businesses be more attractive to customers \\
\hline LTD6 & Green technology innovation helps businesses increase the quality of their products \\
\hline LTD7 & $\begin{array}{l}\text { Green technology innovation helps businesses increase their ability to penetrate the } \\
\text { domestic market }\end{array}$ \\
\hline LTD8 & Green technology innovation helps businesses increase employees' loyalty \\
\hline LTD9 & Green technology innovation helps businesses reduce production costs \\
\hline LTD10 & $\begin{array}{l}\text { Green technology innovation helps businesses be less expensive to purchase input } \\
\text { materials }\end{array}$ \\
\hline LTD11 & Green technology innovation helps businesses be easy to access loans \\
\hline LTD12 & $\begin{array}{l}\text { Green technology innovation helps businesses be successful in conquering foreign } \\
\text { markets }\end{array}$ \\
\hline LTD13 & Green technology innovation helps businesses be creative in creating products \\
\hline \multicolumn{2}{|c|}{ 2. Compatibility } \\
\hline KTT1 & $\begin{array}{l}\text { Green technology innovation is suitable for enterprises' current production and } \\
\text { business activities }\end{array}$ \\
\hline KTT2 & Green technology innovation is consistent with enterprise values \\
\hline KTT3 & Green technology innovation is consistent with the business philosophy of business \\
\hline KTT4 & Green technology innovation is consistent with corporate culture \\
\hline KTT5 & Green technology innovation is consistent with the orientation of enterprises \\
\hline KTT6 & $\begin{array}{l}\text { Innovating green technology is consistent with the existing production processes of } \\
\text { enterprises }\end{array}$ \\
\hline KTT7 & Green technology innovation is consistent with the style of senior leaders of enterprises \\
\hline KTT8 & $\begin{array}{l}\text { Green technology innovation is consistent with the local and national development } \\
\text { orientation }\end{array}$ \\
\hline KTT9 & Green technology innovation is consistent with the trend of international integration \\
\hline \multicolumn{2}{|c|}{ 3. Simplicity } \\
\hline SDD1 & Knowledge of green technology innovation is easy to learn \\
\hline SDD2 & Knowledge of green technology innovation is easy to understand \\
\hline SDD3 & Green technology innovation is easy to practice \\
\hline SDD4 & Knowledge about green technology innovation is easy to share \\
\hline SDD5 & Ease of assessment of green technological innovations \\
\hline SDD6 & Green technology innovation takes little time to become familiar \\
\hline SDD7 & It takes little cost to gradually get used to green technology innovation \\
\hline
\end{tabular}


Nguyen M. Ha, Pham A. Nguyen. HCMCOUJS-Economics and Business Administration, 12(1), 3-19 9

\begin{tabular}{|c|c|}
\hline Items & Indicator variable \\
\hline \multicolumn{2}{|c|}{ II. Green innovation } \\
\hline \multicolumn{2}{|c|}{ 1. Green product } \\
\hline DSP1 & Enterprises prioritize the use of less polluting materials \\
\hline DSP2 & Enterprises prioritize the use of materials that consume fewer resources and energy \\
\hline DSP3 & Enterprises use the least amount of raw materials to create products \\
\hline DSP4 & Enterprises will consider the product's recycling before proceeding with production \\
\hline DSP5 & Enterprises will consider the reuse of products before proceeding with production \\
\hline DSP6 & $\begin{array}{l}\text { Enterprises will consider the decomposition of products before proceeding with } \\
\text { production }\end{array}$ \\
\hline DSP7 & Enterprises are often the first to bring green products to the market \\
\hline DSP8 & Enterprises improve environmentally friendly packaging for products \\
\hline DSP9 & Enterprises use recyclable/reusable packaging \\
\hline \multicolumn{2}{|c|}{ 2. Green process } \\
\hline DQT1 & Enterprise's production process reduces harmful substances \\
\hline DQT2 & wastewater \\
\hline DQT3 & Enterprise's production process reduces emissions \\
\hline DQT4 & Enterprise's production process reduces noise \\
\hline DQT5 & Wastewater from the production process of enterprises is treated to meet standards \\
\hline DQT6 & Wastewater from the production process after being treated is reused by enterprises \\
\hline DQT7 & $\begin{array}{l}\text { Your production process reduces the consumption of raw materials (water, electricity, } \\
\text { coal, or oil) }\end{array}$ \\
\hline DQT8 & Enterprises apply energy conservation technologies \\
\hline DSP9 & Enterprises apply renewable resource technologies \\
\hline DSP10 & Enterprises apply industrial waste recycling technologies \\
\hline DSP11 & Enterprises apply technologies in the process of preventing pollution \\
\hline
\end{tabular}

Source: Kivimaa and Kautto (2010); Lin and Ho (2011); Lin et al. (2013); Rogers (2003); Sia et al. (2004); Wen and Chen (1997)

\section{Research methods and data}

\subsection{Research method}

To determine the impact of technological factors on green innovation, this study had used the quantitative research method. The next step was the stage of analyzing the data collected from the respondents. The Exploratory Factor Analysis (EFA) would be used in this step to consider the factor structure of a set of observed variables in the study. Finally, Structural Equation Modeling (SEM) was employed to place the research hypotheses to the test. In this study, PLS-SEM was used to estimate both the measurement modeling and the structural equation modeling for the proposed research model of the author. Smart-PLS 3.3.2 is also used for both measurement modeling and structural equation modeling. 


\subsection{Sample of the study}

The data for this study came from a questionnaire survey sent directly to respondents from organizations in the manufacturing sector located in Vietnam's main industrial zones. The respondents in this survey were directors of those firms approaching through the focal point of infrastructure companies and industrial park management boards. The reason for choosing the directors as subjects for collecting data is to have a very knowledgeable understanding of the current businesses involved in the decision-making process. The survey was conducted in different groups of respondents who differ in gender, educational background, managerial experience, working seniority in the current firm, a form of business, as well as the frequency of using green products to get the representation for the whole population. Based on the regulation of Hair, Anderson, Babin, and Black (2010) for sampling size when using the Structural Equation Modeling, the suitable size for samples was in the range from 300 to 500 to avoid computation difficulties in analyzing data; therefore, the sample of this survey was collected from 400 respondents working in the industrial zones across the country in the North, South and Middle Region of Vietnam. The convenience sampling method was used as this method due to being helped the author collects the data from the population, which could be available to participate in this study. This study uses the software PLS-Smart 3.3.2 to process quantitative data collected from the collected survey owing to widely use in current studies and accept non-normal distribution data collecting from convenience sampling method.

\section{Findings}

\subsection{Descriptive statistics}

The sample survey was conducted on a group of participants who differed in gender, educational background, managerial seniority, and experience with green products in various provinces and cities throughout Vietnam. The following table describes the characteristics of the collected samples.

\section{Table 2}

Demographic of respondents

\begin{tabular}{|c|c|c|}
\hline Characteristics & Frequency & Percentage $(\%)$ \\
\hline \multicolumn{3}{|l|}{ Gender } \\
\hline Male & 368 & $92.0 \%$ \\
\hline Female & 32 & $8.0 \%$ \\
\hline Total & 400 & $100 \%$ \\
\hline Educational background & Frequency & Percentage $(\%)$ \\
\hline Undergraduate & 9 & $2.25 \%$ \\
\hline Bachelor's degree & 333 & $83.25 \%$ \\
\hline Master / Ph.D. & 58 & $14.5 \%$ \\
\hline Total & 400 & $100 \%$ \\
\hline \multicolumn{3}{|l|}{ Managerial seniority } \\
\hline From 01 year to 03 years & 49 & $12.3 \%$ \\
\hline From 04 years to 06 years & 179 & $44.8 \%$ \\
\hline
\end{tabular}


Nguyen M. Ha, Pham A. Nguyen. HCMCOUJS-Economics and Business Administration, 12(1), 3-19 11

\begin{tabular}{|l|c|c|} 
From 07 years to 09 years & 115 & $28.7 \%$ \\
Over 10 years & 57 & $14.2 \%$ \\
\multicolumn{1}{|c|}{ Total } & $\mathbf{4 0 0}$ & $\mathbf{1 0 0 \%}$ \\
\hline Frequency of using green products \\
\hline Never & 180 & $45.0 \%$ \\
From once to thrice & 170 & $42.5 \%$ \\
More than 94 times & 50 & $11.5 \%$ \\
\multicolumn{1}{|c|}{ Total } & $\mathbf{4 0 0}$ & $\mathbf{1 0 0 \%}$ \\
\hline
\end{tabular}

Source: The researcher's data analysis

\subsection{Measurement modeling}

According to Hulland (1999), when analyzing data with Smart-PLS, indicators that needed to evaluate in the measurement modeling included outer loadings (relationship between indicators and reflective construct), reliability, convergent validity, and discriminant validity. In this study, the outer loadings of observed variables were all larger than 0.7 (> 0.7) shown in Table 3 below, so that all observed variables had meanings in the modeling.

Table 3

Outter loadings

\begin{tabular}{|l|l|l|l|l|}
\hline & DMX & KTT & LTD & SDD \\
\hline DQT3 & 0.834 & & & \\
\hline DQT6 & 0.803 & & & \\
\hline DQT9 & 0.818 & & & \\
\hline DSP3 & 0.861 & & & \\
\hline DSP6 & 0.805 & & & \\
\hline DSP7 & 0.780 & & & \\
\hline DSP9 & 0.803 & & & \\
\hline KTT1 & & 0.788 & & \\
\hline KTT2 & & 0.794 & & \\
\hline KTT3 & & 0.783 & & \\
\hline KTT4 & & 0.770 & & \\
\hline KTT5 & & 0.803 & & \\
\hline LTD11 & & & 0.816 & \\
\hline LTD2 & & & 0.827 & \\
\hline LTD3 & & & 0.779 & \\
\hline LTD5 & & & 0.784 & \\
\hline LTD8 & & & 0.866 & \\
\hline
\end{tabular}




\begin{tabular}{|l|l|l|l|l|}
\hline & DMX & KTT & LTD & SDD \\
\hline SDD1 & & & & 0.776 \\
\hline SDD2 & & & & 0.829 \\
\hline SDD3 & & & & 0.832 \\
\hline SDD5 & & & & 0.760 \\
\hline SDD6 & & & & 0.788 \\
\hline SDD7 & & & & 0.771 \\
\hline
\end{tabular}

Source: Data analysis from Software Smart-PLS, version 3.3.2

In addition, the Cronbach's Alpha of all scales was greater than 0.7 (> 0.7), indicating that all scales were reliable. As shown in Table 4 below, all scales had convergent validity because their Composite Reliability was greater than 0.7 and their Average Variance Extracted was greater than 0.5 .

Table 4

Construct reliability and validity of factors

\begin{tabular}{|l|r|r|r|r|}
\hline & Cronbach's Alpha & rho_A & Composite Reliability & $\begin{array}{l}\text { Average Variance } \\
\text { Extracted (AVE) }\end{array}$ \\
\hline DMX & 0.916 & 0.919 & 0.933 & 0.665 \\
\hline KTT & 0.848 & 0.857 & 0.891 & 0.620 \\
\hline LTD & 0.874 & 0.894 & 0.908 & 0.664 \\
\hline SDD & 0.896 & 0.903 & 0.918 & 0.615 \\
\hline
\end{tabular}

Source: Data analysis from Software Smart-PLS, version 3.3.2

All values of discriminant validity in this study were replied to on the rule of Fornell and Larker (1981) when testing the Measurement modeling with observed variables and measurement error. The analysis revealed that the smallest square root of AVE was greater than the greatest value of correlations among latent variables, as shown in Table 5 below; thus, discriminant validity was guaranteed.

Table 5

Fornell-Larcker Criterion

\begin{tabular}{|l|l|l|l|l|}
\hline & DMX & KTT & LTD & SDD \\
\hline DMX & 0.815 & & & \\
\hline KTT & 0.347 & 0.787 & & \\
\hline LTD & 0.360 & 0.385 & 0.815 & \\
\hline SDD & 0.335 & 0.257 & 0.283 & 0.784 \\
\hline
\end{tabular}

Source: Data analysis from Software Smart-PLS, version 3.3.2 


\subsection{Testing the research hypothesis}

The criteria to evaluate the quality of PLS-SEM, as well as steps to test hypotheses in this study, were replied on the evaluating suggestions of Hair, Hult, Ringle, and Sarstedt (2016). According to Hair et al. (2016), there was no suitable measurement for the whole PLS-SEM; therefore, the quality of the model was evaluated by R square, Variance Inflation Factor (VIF), Path Coefficients, and Effect Size $\left(\mathrm{f}^{2}\right)$. The result in Table 6 showed that R square (R2) was in the range from 0 to 1 (when approaching closely to 1 , it means that independent variables explain more for dependent variables) so that the structural modeling had good quality.

Table 6

R Square

\begin{tabular}{|c|c|c|}
\hline & R Square & R Square Adjusted \\
\hline DMX & 0.218 & 0.218 \\
\hline
\end{tabular}

Source: Data analysis from Software Smart-PLS, version 3.3.2

From Table 6 above, it can be seen that the R square adjusted of the independent factor (DMX) was 0.218; therefore, the observed variables explained $21.8 \%$ of the upheaval of DMX.

\section{Table 7}

Inner VIF values

\begin{tabular}{|c|c|c|c|}
\hline & LTD & KTT & SDD \\
\hline DMX & 1.208 & 1.226 & 1.118 \\
\hline
\end{tabular}

Source: Data analysis from Software Smart-PLS, version 3.3.2

To evaluate the multicollinearity, the author used the result of Variance Inflation Factor (VIF) when analyzing PLS-SEM. According to Hair et al. (2016), if VIF is from 5 or more, the model may highly have the multicollinearity phenomenon. As seen in Table 7 above, the research result showed that all VIF indexes were smaller than $5(<5)$; therefore, the author could conclude that there was no multicollinearity in the structural modeling.

When evaluating the Effect Size of factors, the author based on Cohen's criterion (1988) as follows: if $\mathrm{f}^{2}<0.02$ : very small or no effect; $\mathrm{f}^{2} \geq 0.02$ : small effect, $\geq 0.15$ : medium effects, $\geq$ 0.35: large effects.

\section{Table 8}

f Square

\begin{tabular}{|l|l|l|l|}
\hline & LTD & KTT & SDD \\
\hline DMX & 0.046 & 0.050 & 0.056 \\
\hline
\end{tabular}

Source: Data analysis from Software Smart-PLS, version 3.3.2

From Table 8 above, it can be concluded that Relative advantage (LTD), Compatibility $(K T T)$, and Simplicity $(S D D)$ had all small effects on the green innovation of firms with those factors $\mathrm{f}^{2}>0.02$. 


\section{Table 9}

Result of testing hypotheses

\begin{tabular}{|c|l|r|r|c|}
\hline Hypothesis & \multicolumn{1}{|c|}{ Hypothesis path } & Path coefficients & P Values & Result \\
\hline H1 & LTD -> DMX & 0.218 & 0.000 & Accepted \\
\hline H2 & KTT -> DMX & 0.207 & 0.000 & Accepted \\
\hline H3 & SDD -> DMX & 0.220 & 0.000 & Accepted \\
\hline
\end{tabular}

Source: Data analysis from Software Smart-PLS, version 3.3.2

After testing the concepts for reliability and validity, structural modeling was used to test the relationship between research hypotheses. The result of the testing hypothesis with Path coefficients and $\mathrm{P}$ values in Table 9 showed that $\mathrm{H} 1, \mathrm{H} 2$, and $\mathrm{H} 3$ were accepted. It proved that Relative advantage and Compatibility impacted positively on green innovation of firms with path coefficient as 0.207 (Sig. $=0.000<0.05$ ) and 0.218 (Sig. $=0.000<0.05$ ) respectively. Additionally, Simplicity also affected positively green innovation with path coefficient as 0.220 (Sig. $=0.000<0.05)$.

All the path coefficients of factors were shown in the following figure of structural modeling:

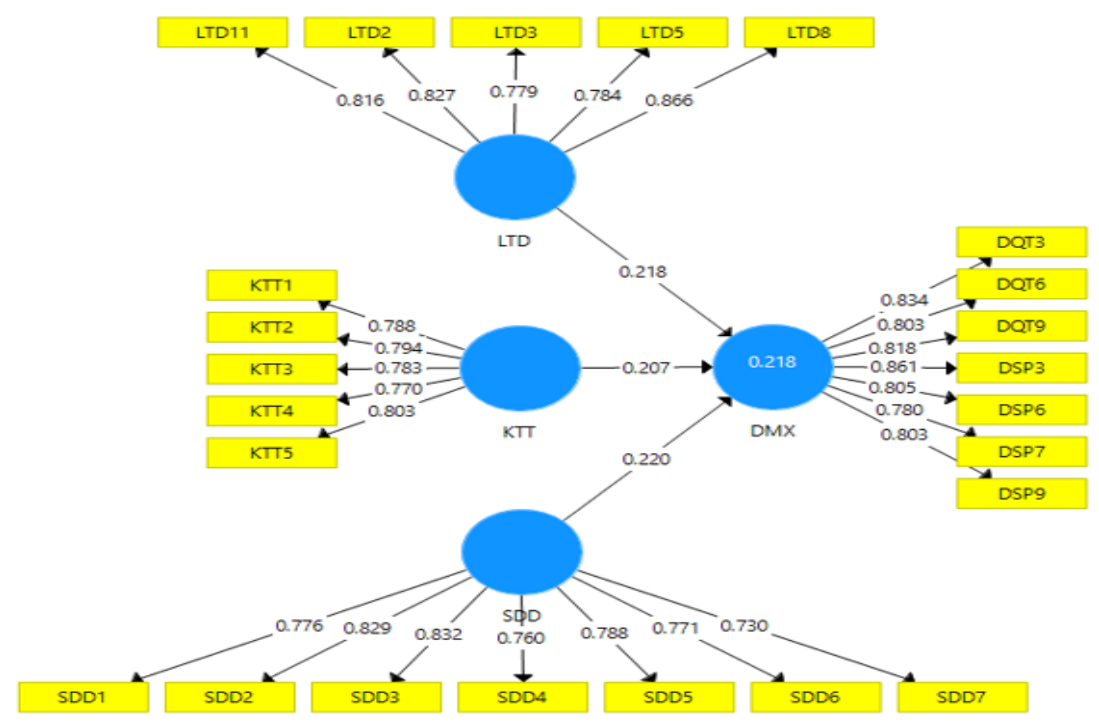

Figure 2. The structural equation modeling of the study

\subsection{Result discussion}

With impact of $\beta=0.218$ and $\mathrm{P}$ values $=0.000<0.05$, it can be concluded that $\mathrm{H} 1$ was supported which meant Relative advantage influenced positively on green innovation. The study's findings are relevant to the study's proposed hypothesis. This is the second strongest impact in the relationship between characteristics of technological factors and green innovation. The research result is consistent with the results of previous studies (Afuah, 1998; Del Río González; 2005; Le, Hollenhorst, Harris, McLaughlin, \& Shook, 2006) as well as with the theory of Rogers's innovation diffusion theory (2003), the relative advantage is the main predictor in terms of adoption innovation. Therefore, with relative advantage in innovating green technology, companies can differentiate themselves from others by offering unique forms of new product and services products and also can achieve a great deal of superiority over their competitors competing 
in the same industry and the same production area. The findings of the study also demonstrated that businesses should indeed consider the advantages of green innovation over existing technology when making decisions about the adoption of innovations that can assist firms in successfully operating in the economic market.

For Compatibility, with an impact of $\beta=0.207$ and $\mathrm{P}$ values $=0.000$, it meant $\mathrm{H} 2$ was supported which meant Compatibility positively affected green innovation. The research result is consistent with the results of previous studies (Beise \& Rennings, 2005; Kemp et al., 2001; Le et al., 2006; Weng \& Lin, 2011) as well as with the theory of Rogers's innovation diffusion theory (2003) that Compatibility is a primary predictor in terms of adoption innovation. Businesses will be more likely to adopt innovation when they find that innovation is more compatible with their current business activities. Technological innovation towards green economic development is the appropriate direction and in line with the new development trend of the business today, not only bringing benefits to businesses but also bringing efficiency in the long term to transition to a green economy.

For Simplicity, with an impact of an $\beta=0.220$ and $\mathrm{P}$ values $=0.000$, it meant $\mathrm{H} 3$ was supported, which meant Simplicity positively affected green innovation. The research result is consistent with the results of previous studies (Beise \& Rennings, 2005; Kemp et al., 2001; Le et al., 2006; Weng \& Lin, 2011) as well as with the theory of Rogers's innovation diffusion theory (2003) that Simplicity is a determinant affecting positively on green innovation. The results reinforced the statement of previous studies that technology complexity negatively and significantly affects the adoption of green innovations (Kousar et al., 2017; Lin \& Ho, 2011; Rogers, 2003; Tornatzky \& Klein, 1982). It implied that firms with a lack of technical expertise or human resources are less willing to embrace innovation. When innovations become simple, easy to learn, and use, they are more likely to adopt green innovations and play their role in reducing negative environmental impact.

\section{Conclusion and recommendation}

To pursue effective sustainability, environmental aspects are recognized as primary consideration worldwide. During the operation, manufacturing firms have been causing greenhouse gas emissions as well as hazardous substances. Businesses pay little attention to community and social wellbeing and environment; they mostly focus on organizational profits and are afraid to invest in green technology to protect the environment due to the costs affecting the profits of enterprises (Nham, 2012). To improve the environmental situation, businesses need to consider environmental protection issues in order to gain a competitive advantage in the market as well as financial performance (Lin \& Ho, 2011).

The purpose of this empirical study was to examine the association between technological factors and green innovation of firms in manufacturing sectors located in Vietnam's main industrial zones. The majority of studies have focused on organizational and environmental factors, resulting in a scarcity of research focusing on the impact of technological factors on green innovation adoption. This study contributes to the literature a vision that technological factors have potentially significant influences on the adoption of green innovation. The result of analyzing the measurement modeling and structural modeling of PLS-SEM has indicated that all three characteristics of technology, including Relative advantage, Compatibility, and Simplicity affected positively on green innovation. From the result of the study, it can be concluded that the contribution of the paper became an important element to motivate Vietnamese enterprises to realize the significance of technological factors in the adoption of green practice to have a relevant strategy and principal to sustain the firm effectively. In addition, it can enhance the self- 
consciousness of enterprises to actively participate in green innovation, improving their firm performance and environmental performance, as well as have a part in protecting the environment and developing a green economy in Vietnam. Therefore, future environmental management research should consider technological factors. Furthermore, the findings of this study reveal the various industries that could react differently to environmental challenges to improve their economic performance. Based on the findings of the study, the author proposed the following policies for enterprise administrators to improve their performance when implementing green innovation: (1) being active in investing and researching high-tech innovations to increase productivity while conserving natural resources; (2) reasonably allocating budget to change new technology because the majority of SMEs due to their capital capacity is not strong enough to access new technology as well as human resource training policies for implementing green innovation; (3) promulgating mechanisms and policies or necessary measures to encourage enterprises to increase investment in green technology for contributing to the protection of the environment; (4) actively grasping the general global trend, worldwide green technology implementing and moving towards, choosing the right technologies suit with the firms for developing in the most effective direction.

Same as other studies, this research still has some limitations. Firstly, the survey only focused on identifying the impacts of technological factors on green innovation in Vietnam's manufacturing sector, whereas some factors can impact the adoption of green practices. Future studies should discuss and consider other factors, including external factors, environmental factors as well as organizational factors, to find out and compare the effects of each factor on green innovation. Secondly, this survey was conducted only in the manufacturing sector while there are many firms in different business fields. Hence, future studies should be conducted to examine other business fields for getting general evaluations towards green innovation. Thirdly, the convenience sampling method was only applied in this research, which is regarded as a type of non-probability sampling method to collect the data, while other sampling methods have many advantages. Finally, future studies may apply the proposed model to different contexts owing to the result varying differently in different countries, industrial sectors, or green practices.

\section{References}

Afuah, A. (1998). Innovation management: Strategies, implementation, and profits. New York, NY: Oxford University Press.

Aragon-Correa, J. A., \& Sharma, S. (2003). A contingent resource-based view of proactive corporate environmental strategy. Academy of Management Review, 28(1), 71-88.

Bansal, P. (2005). Evolving sustainably: A longitudinal study of corporate sustainable development. Strategic Management Journal, 26(3), 197-218.

Beise, M., \& Rennings, K. (2005). Lead markets and regulation: A framework for analyzing the international diffusion of environmental innovations. Ecological Economics, 52(1), 5-17.

Berrone, P., Fsfuri, A., Gelabert, L., \& Gomez-Mejia, L. R. (2013). Necessity as the mother of "green" innovation: Institutional pressures and environmental innovation. Strategic Management Journal, 34(8), 891-909.

Borsatto, J. M. L. S., \& Amui, L. B. L. (2019). Green innovation: Unfolding the relation with environmental regulations and competitiveness. Resources, Conservation and Recycling, $149(1), 445-454$. 
Chiou, T. Y., Chan, H. K., Lettice, F., \& Chung, S. H. (2011). The influence of greening the suppliers and green innovation on environmental performance and competitive advantage in Taiwan. Transportation Research Part E: Logistics and Transportation Review, 47(6), 822-836.

Christmann, P. (2004). Multinational companies and the natural environment: Determinants of global environmental policy standardization. Academy of Management Journal, 47(5), 747-760.

Cohen, J. (1988). Statistical power analysis for the behavioral sciences (2nd ed.). Hillsdale, NJ: Lawrence Erlbaum Associates.

Del Río González, P. (2005). Analyzing the factors influencing clean technology adoption: A study of the Spanish pulp and paper industry. Business Strategy and the Environment, 14(1), 20-37.

Etzion, D. (2007). Research on organizations and the natural environment, 1992-present: A review. Journal of Management, 33(4), 637-664.

Fornell, C., \& Larker, D. F. (1981). Structural equation models with unobservable variables and measurement error: Algebra and statistics. Journal of Marketing Research, 18(2), 39-50.

Frambach, R. T., \& Schillewaert, N. (2002). Organizational innovation adoption: A multi-level framework of determinants and opportunities for future research. Journal of Business Research, 55(2), 163-176.

Gonzalez-Benito, J., \& Gonzalez-Benito, O. (2006). A review of determinant factors of environmental proactivity. Business Strategy and the Environment, 15(2), 87-102.

Guo, Y., Xia, X., Zhang, S., \& Zhang, D. (2018). Environmental regulation, government R\&D funding, and green technology innovation: Evidence from China provincial data. Sustainability, 10(4), 1-21.

Hair, J. F., Anderson, R. E., Babin, B. J., \& Black, W. C. (2010). Multivariate data analysis: A global perspective (7th ed.). Upper Saddle River, NJ: Pearson Education.

Hair, J. F., Hult, G. T. M., Ringle, C., \& Sarstedt, M. (2016). A Primer on Partial Least Squares Structural Equation Modeling (PLS-SEM) (2nd ed.). Thousand Oaks, CA: Sage Publications Inc.

Henriques, I., \& Sadorsky, P. (2007). Environmental technical and administrative innovations in the Canadian Manufacturing Industry. Business Strategy and the Environment, 16(2), 119-132.

Ho, A. H. (2015). Business compliance with environmental regulations: Evidence from Vietnam. Retrieved December 26, 2021, from http://veam.org/wp-content/uploads/2016/08/2015_ 16_Hoang-Anh_Ho_Business_Compliance_with_Environmental_Regulations.pdf

Hulland, J. (1999). Use of Partial Least Squares (PLS) in strategic management research: A review of four recent studies. Strategic Management Journal, 20(2), 195-204.

Jeyaraj, A., Rottman, J. W., \& Lacity, M. C. (2006). A review of the predictors, linkages, and biases in IT innovation adoption research. Journal of Information Technology, 21(1), 1-23.

Kemp, R., Arundel, A., \& Smith, K. (2001). Survey indicators for environmental innovation. Paper presented at the Conference Towards Environmental Innovation Systems in GarmischPartenkirchen. 
Kimberly, J. R., \& Evanisko, M. J. (1981). Organizational innovation: The influence of individual, organizational, and contextual factors on hospital adoption of technological and administrative innovations. Academy of Management Journal, 24(4), 689-713.

Kivimaa, P., \& Kautto, P. (2010). Making or breaking environmental innovation? Technological change and innovation markets in the pulp and paper industry. Management Research Review, 33(4), 289-305.

Kleindorfer, P. R., Singhal, S., \& Wassenhove, L. N. V. (2005). Sustainable operations management. Production and Operations Management, 14(4), 482-492.

Kousar, S., Sabri, P. S. U., Zafar, M., \& Akhtar, A. (2017). Technological factors and adoption of green innovation - Moderating role of government intervention: A case of SMEs in Pakistan. Pakistan Journal of Commerce and Social Sciences, 11(3), 833-861.

Lai, S. B., Wen, C. T., \& Chen, Y. S. (2003, December). The exploration of the relationship between the environmental pressure and the corporate competitive advantage. Paper presented at the 2003 CSMOT Academic Conference, Hsinchu, Taiwan.

Le, Y., Hollenhorst, S., Harris, C., McLaughlin, W., \& Shook, S. (2006). Environmental management: A study of Vietnamese hotels. Annals of Tourism Research, 33(2), 545-567.

Lee, S. (2008). Drivers for the participation of small and medium-sized suppliers in green supply chain initiatives. Supply Chain Management (SCM), 13(3), 185-198.

Lin, C. Y., \& Ho, Y. H. (2011). Determinants of green practice adoption for logistics companies in China. Journal of Business Ethics, 98(1), 67-83.

Lin, R. J., Tan, K. H., \& Geng, Y. (2013). Market demand, green product innovation, and firm performance: Evidence from Vietnam motorcycle industry. Journal of Cleaner Production, 40(1), 101-107.

Moisander, J. (2007). Motivational complexity of green consumerism. International Journal of Consumer Studies, 31(4), 404-409.

Nham, T. P. (2012). The impact of environmental performance on the performance of small and medium-sized manufacturing enterprises in Vietnam. VNU Journal of Science, Economics and Business, 28(5), 1- 16.

Nishant, R., Teo, T. S. H., Goh, M., \& Krishnan, S. (2012). Does environmental performance affect organizational performance? Evidence from green its organization. Retrieved December 26, 2021, from https://www.researchgate.net/publication/281639418_Does_ Environmental_Performance_Affect_Organizational_Performance_Evidence_from_Green _IT_Organizations

O'Rourke, D. (2004). Community-driven regulation: Balancing development and the environment in Vietnam. Cambridge, MA: MIT Press.

Rave, T., Goetzke, F., \& Larch, M. (2011). The determinants of environmental innovations and patenting: Germany reconsidered (Ifo Working paper no.97). Retrieved December 26, 2021, from https://www.econstor.eu/bitstream/10419/73719/1/IfoWorkingPaper-97.pdf

Rogers, E. M. (2003). Diffusion of innovations. New York, NY: Free Press.

Ruslan, M. F., Senin, A. A., \& Soehod, K. (2014). Technological determinants of green production adoption by Malaysian Small and Medium Enterprises (SMEs): A conceptual framework. International Conference on Business, Management \& Corporate Social Responsibility, $1(1), 59-63$. 
Russo, M. V., \& Fouts, P. A. (1997). A resource-based perspective on corporate environmental performance and profitability. Academy of Management Journal, 40(3), 534-559.

Salihu, A. C., Nabegu, A. B., Abdulkarim, B., \& Mútapha, A. (2016). Analysis of the factors affecting facilities compliance to environmental regulations in Minna - Niger State, Nigeria. World Scientific News, 45(2), 174-184.

Seman, N. A. A., Zakuan, N., Jusoh, A., Arif, M. S. M., \& Saman, M. Z. M. (2012). The relationship of green supply chain management and green innovation concept. Procedia Social and Behavioral Sciences, 57(1), 453-457.

Sia, C. L., Teo, H. H., Tan, B. C. Y., \& Wei, K. K. (2004). Effects of environmental uncertainty on organizational intention to adopt distributed work on engineering management. IEEE Transactions on Engineering Management, 51(3), 253-267.

Tornatzky, L. G., \& Klein, K. J. (1982). Innovation characteristics and innovation adoption-implementation: A meta-analysis of findings. IEEE Transactions on Engineering Management, 29(1), 28-45.

Tornatzky, L. G., Fleischer, M., \& Chakrabarti, A. K. (1990). The processes of technological innovation. Lexington, MA: Lexington Books.

Velena, V., \& Ellenbecker, M. (2001). Indicators of sustainable production: Framework and methodology. Journal of Cleaner Production, 9(6), 519-549.

Walker, K., \& Wan, F. (2012). The harm of symbolic actions and green-washing: Corporate actions and communications on environmental performance and their financial implications. Journal of Business Ethics, 109(2), 227-242.

Wen, C. T., \& Chen, T. M. (1997). The exploration of the organizations of green innovation in Taiwan. National Taiwan University Management Review, 8(2), 99-124.

Weng, M. H., \& Lin, C. Y. (2011). Determinants of green innovation adoption for Small and Medium-Sized Enterprises (SMEs). African Journal of Business Management, 5(22), 9154-9163.

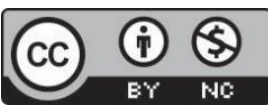

Creative Commons Attribution-NonCommercial 4.0 International License. 